\title{
A NOVEL MODEL OF CONTINUOUS DEPLETION OF GLUTATHIONE IN MICE TREATED WITH L-BUTHIONINE (S,R)-SULFOXIMINE
}

\author{
Toshiyuki WATANABE, Hideki SAGISAKA, Shingo ARAKAWA, Yukari SHIBAYA, Mayumi WATANABE, \\ Isao IGARASHI, Kohji TANAKA, Shigeo TOTSUKA, Wataru TAKASAKI and Sunao MANABE \\ Medicinal Safety Research Laboratories, Sankyo, Co., Ltd., \\ 717 Horikoshi, Fukuroi, Shizuoka 437-0065, Japan
}

(Received August 26, 2003; Accepted November 5, 2003)

\begin{abstract}
L-Buthionine (S,R)-sulfoximine (BSO), an inhibitor of glutathione (GSH) synthesis, was administered to mice via drinking water for 14 days in order to establish an animal model with continuously depleted levels of GSH. No toxicity was observed at $20 \mathrm{mM} \mathrm{BSO}$, even though a significant decrease in liver weight was observed at $30 \mathrm{mM}$ BSO. GSH levels in the liver, kidney, brain, lung, heart, spleen, pancreas, small intestine, large intestine, skeletal muscle, plasma and blood cells from mice given $20 \mathrm{mM}$ of BSO were all less than those from the control mice continuously throughout a 24 -hr period. The ratios of the GSH levels to that of the control were $46.4 \%$ and $16.7 \%$ in the liver and kidney, respectively, suggesting a decrease in GSH conjugation activity in vivo by GSH depletion. Liver cytochrome P450 content and UDP-glucuronosyltransferase activity to $p$-nitrophenol were not influenced by the BSO dosing. To confirm the adequacy of this GSH-depletion model, 0.125 or $0.25 \%$ of acetaminophen (APAP) was administered via diet to this model for 14 days. Nine out of the ten mice given both $20 \mathrm{mM}$ BSO and $0.25 \%$ APAP died on Day 2, and remarkable necrosis was observed in the hepatocytes and renal tubular epithelium. Moreover, focal necrosis of hepatocytes with proliferation of fibroblasts was observed on Day 15 in some mice coadministered $20 \mathrm{mM}$ BSO and $0.125 \%$ APAP. However, no toxicity was observed in mice given APAP alone. Based on these results, a mouse given $20 \mathrm{mM}$ of BSO via drinking water for 14 days was concluded to be an animal model with continuously depleted levels of GSH in various organs without toxicity. This model shows high susceptibility to toxicity induced by chemicals which are metabolized to electrophilic and reactive metabolite(s), such as APAP.
\end{abstract}

KEY WORDS: Glutathione depletion, L-Buthionine (S,R)-sulfoximine, Acetaminophen, Reactive intermediate, Liver, Idiosyncrasy

\section{INTRODUCTION}

Glutathione (5-L-glutamyl-L-cysteinylglycine, $\mathrm{GSH}$ ) is a ubiquitous tripeptide of glycine, glutamic acid and cysteine. It serves a vital function in protecting tissues against the degenerating effects of oxidative damage by scavenging the free radicals from endogenous or exogenous agents (Reed, 1986; Lu, 1999). As a nucleophile, GSH also reacts with electrophilic and reactive intermediates derived from exogenous chemicals such as drugs, and protects nucleic acids and proteins from them. Such reactions are often mediated by glutathione S-transferases (GSTs, Coles and Ketterer, 1990; Lu, 1999). Susceptibility to chemicals metabo- lized to electrophilic and reactive metabolite(s) including intermediate(s) is thus different between GSHdepleted and normal animals (Miners et al., 1984; Mizutani et al., 1987, 1999; Boughattas et al., 1996) or between GST-deficient and non-deficient humans (Poppel et al., 1992). A GST-deficient animal may be useful for the investigation of the toxicity mechanism induced by chemicals if those chemicals are conjugated with GSH by the deficient GST isozyme. A more useful model may be a GSH-depleted animal, because the total ability of GSH conjugation is decreased by the GSH depletion. There are two types of GSH-depletor: one acts as an eliminator of GSH; and the other acts as an inhibitor of GSH synthesis. Generally, a GSH elim- 
inator is not suitable for mechanistic study of toxicity induced by a chemical because of the competition for GSH conjugation between the chemical and the GSH eliminator itself. That is to say, the chemical-induced toxicity may not potentiate to a serious enough level even if the chemical in question is coadministered with the GSH eliminator. Thus, a GSH depletor should be selected as the inhibitor of GSH synthesis to investigate the relationship between the total ability of GSH conjugation and the toxicity induced by a chemical.

L-Buthionine-S,R-sulfoximine (BSO) is wellknown as an inhibitor of GSH synthesis (Griffith and Meister, 1979a), and has been reported to inhibit the rate-limiting enzyme of GSH synthesis, $\gamma$-glutamylcysteine synthetase $(\gamma-\mathrm{GCS})$, specifically and irreversibly (Griffith, 1982). GSH levels in the liver, kidney, pancreas and skeletal muscle are rapidly decreased after a single dosing of BSO to mice and rats (Griffith and Meister, 1979b). Moreover, it has been shown that pre-dosing of BSO potentiates the toxicity of chemicals which are detoxified by GSH more strongly than no treatment with BSO (Miners et al., 1984; Mizutani et al., 1987, 1999; Boughattas et al., 1996). It has also been reported that the GSH levels in some tissues such as the heart and spleen show little decrease after a single dosing of BSO to mice. However, 14-day dosing of $\mathrm{BSO}$ via drinking water induced a significant decrease in GSH levels in almost all the tissues except for the brain (Griffith and Meister, 1979b). These reports suggest that a mouse administered BSO via drinking water for 14 days may be a suitable model for GSH depletion, although certain critical factors such as toxicity of BSO and durability of GSH depletion after multiple BSO dosing have not been studied yet.

In the present paper, durability of GSH depletion, toxicity and changes in the levels of drug-metabolizing enzymes were investigated in mice with continuously depleted levels of GSH by BSO via drinking water for 14 days to establish and validate an in vivo sensitive detection model of toxicity induced by a chemical. Additionally, the mice treated with BSO were simultaneously administered acetaminophen ( $N$-acetyl- $p$-aminophenol, APAP), which is known to be biotransformed to a chemically reactive metabolite, $N$-acetyl- $p$-benzoquinoneimine (Dahlin et al., 1984) or some other radical species (Moldeus et al., 1982), resulting in liver and kidney injury (Boyer and Rouff, 1971; Hinson, 1980). This combination study of BSO and APAP revealed the usefulness of the GSH depletion model for mechanistic toxicity studies, because it has been reported that GSH conjugation is one of the most important detoxication of chemically reactive metabolites of APAP.

\section{MATERIALS AND METHODS}

\section{Chemicals}

BSO (Fig. 1, purity: >97\%) and APAP (purity: $>99 \%$ ) were purchased from Sigma-Aldrich Japan Co. (Tokyo, Japan). All chemicals and solvents used were of analytical grade.

\section{Test animals and housing conditions}

Male $\mathrm{B} 6 \mathrm{C} 3 \mathrm{~F}_{1}$ mice purchased from Japan SLC, Inc. (Shizuoka, Japan) were used for the present study. Animals were transferred to an animal room at 5 weeks of age. They were kept in a controlled environment at a room temperature of $23 \pm 2^{\circ} \mathrm{C}$ and humidity of $55 \pm$ $10 \%$ with an illumination period of $12 \mathrm{hr}$ (7:00 to 19:00) per day. All animals were housed individually in bracket cages and fed ad libitum with a solid feed (Certified Rodent Diet 5002: PMI Nutrition International, Inc., Tokyo, Japan) sterilized by radiation (irradiated with a ${ }^{60} \mathrm{Co}-\gamma$ ray of $30 \mathrm{kGy}$ ) and tap water was supplied via a water bottle (CLEA Japan, Inc., Tokyo, Japan). At the initiation of BSO administration, animals were 6 weeks old.

\section{Study design}

1. Study 1

To investigate the effect of BSO on toxicity and the levels of GSH and various drug-metabolizing enzymes, mice were treated with BSO via drinking water for 14 days at dose levels of $0,5,10,20$ or 30 $\mathrm{mM}$. In this study, actual dose levels were calculated from the amount of water drunk and were $0,252,536$, 995 and $1502 \mathrm{mg} / \mathrm{kg} /$ day on average, respectively. Each group was composed of four animals. On the day of autopsy, mice were euthanized and autopsied at 9:00.

\section{Study 2}

To investigate the durability of GSH depletion, mice were treated with BSO via drinking water for 14

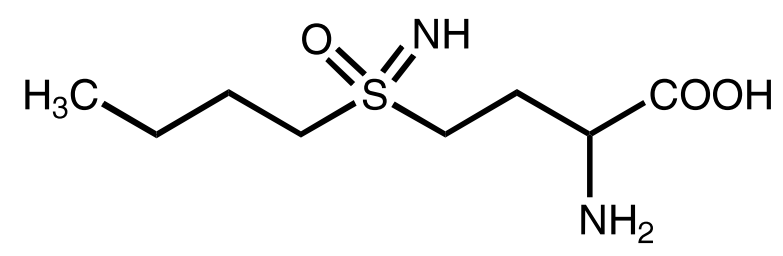

Fig. 1. Chemical structure of BSO. 
Novel model of continuous depletion of GSH induced by BSO.

days at dose levels of 0 or $20 \mathrm{mM}$ (actual average dose level measured: $1072 \mathrm{mg} / \mathrm{kg} / \mathrm{day}$ ). Each group was composed of 24 animals. On the day of autopsy, four mice from each group were euthanized and autopsied at 1:00, 5:00, 9:00, 13:00, 17:00 and 21:00.

\section{Study 3}

To investigate the possibility of whether APAPinduced toxicity was potentiated by simultaneous dosing of BSO, mice were treated with BSO via drinking water at the concentration of 0 or $20 \mathrm{mM}$ (actual average dose level measured: 613 to $843 \mathrm{mg} / \mathrm{kg} / \mathrm{day}$ ), and with APAP via the diet at the concentration of $0,0.125$ or $0.25 \%$ (actual average dose level measured: 196 to $488 \mathrm{mg} / \mathrm{kg} / \mathrm{day}$ ) for 14 days. All groups were composed of 10 animals. On the day of autopsy, mice were euthanized and autopsied at 9:00.

\section{Measurement of BSO dissolved in tap water}

To confirm the stability of BSO in tap water, the concentration of BSO was determined using a highperformance liquid chromatograph (HPLC) system (Waters 2690 Separation Module System, Waters Co., MA, USA). The HPLC conditions were as follows: column, L-column ODS $(150 \mathrm{~mm} \times 4.5 \mathrm{~mm}$ I.D., Chemical Evaluation and Research Institute, Tokyo, Japan); column temperature, $40^{\circ} \mathrm{C}$; mobile phase, 10 $\mathrm{mM}$ phosphate buffer $(\mathrm{pH} 7.0) /$ methanol $=90 / 10$; flow rate, $1.0 \mathrm{~mL} / \mathrm{min}$; injection volume, $70 \mu \mathrm{L}$; UV detector wavelength, $220 \mathrm{~nm}$; and sample cooler temperature, $4^{\circ} \mathrm{C}$. The residual percentages of BSO in both the solutions prepared at $0.1 \%(4.5 \mathrm{mM})$ and $1 \%(45 \mathrm{mM})$ were $101 \%$ after storage for 15 days at $23^{\circ} \mathrm{C}$ without light-shielded conditions. Based on this result, it was concluded that BSO, which was prepared at concentrations of 5 to $30 \mathrm{mM}$, was stable during the 14-day dosing period.

\section{General observations}

The first day of administration was defined as Day 1 in the present report. Mortality and clinical signs were monitored daily during the treatment period. Body weight was measured on Days 1, 5, 8, 12 and 15. Food and water intakes were measured on Days 5, 8, 12 and 15.

\section{Blood biochemical examination}

On the day of autopsy, all mice in Studies 1 and 2 , and 5 out of the 10 mice/group in Study 3 were anesthetized with ether, and blood samples were collected from the inferior vena cava. Plasma was separated from these blood samples, and aspartate aminotransferase (AST), alanine aminotransferase (ALT), alkaline phosphatase (ALP), total bilirubin (T.BIL), total cholesterol (T.CHO), triglyceride (TG), glucose (GLU), total protein (T.PRO), albumin (ALB), albu$\mathrm{min} /$ globulin ratio $(\mathrm{A} / \mathrm{G})$, urea nitrogen $(\mathrm{UN})$, creatinine (CRE), calcium $(\mathrm{Ca})$ and inorganic phosphorus (IP) levels were determined with an automatic analyzer, TBA-200FR (Hitachi, Ltd., Tokyo, Japan).

On Day 2 in Study 3, ALT and CRE levels were determined using a small amount of plasma obtained from the blood via the infraorbital venous plexus of all mice with an analyzer, 5500V (Fujitsu Limited, Tokyo, Japan).

\section{Hematological examination}

In Study 3, hematological examination was performed. On the day of autopsy, 5 out of the 10 mice/ group, namely, those not subjected to blood biochemical examination, were anesthetized with ether, and blood samples were collected from the inferior vena cava. These samples were mixed with $15 \%$ EDTA-2K, and then red blood cell (RBC), hemoglobin (HB), hematocrit (HT), mean corpuscular hemoglobin $(\mathrm{MCH})$, mean corpuscular volume (MCV), mean corpuscular hemoglobin concentration (MCHC), reticulocyte (RET), white blood cell (WBC), differential leukocyte (WBC\%), absolute neutrophil (ANE), absolute lymphocyte (ALY) and platelet (PLT) were determined or counted with an automated blood cell counter, an ADVIA120 (Bayer Medical Ltd., Tokyo, Japan) or MICROX HEG-120NA (Sysmex Corp., Kobe, Japan).

\section{Macroscopic examination}

Macroscopic observations of organs and tissues were performed in all the studies at autopsy. The liver, kidney, brain, lung, heart and spleen were removed and weighed, and then the pancreas, small intestine (ileum), large intestine (colon) and skeletal muscle (right femoris) were also removed.

\section{Histopathological examination}

In Study 3, histopathological examination of the same organs and tissues as for the macroscopic examination described above was performed. The extirpated organs and tissues from the same mice that were subjected to hematological examination were fixed in buffered neutral $10 \%$ formalin. They were embedded in paraffin and sectioned at a thickness of $2-3 \mu \mathrm{m}$, and the sections were stained with hematoxylin-eosin 
(H\&E) for microscopic examinations.

\section{Total GSH assay}

Total GSH (the sum of both the reduced and oxidized forms) was assayed in all the studies. The liver, kidney, brain, lung, heart, spleen, pancreas, small intestine (ileum), large intestine (colon), skeletal muscle (right femoris), plasma and blood cells were obtained from all mice for Studies 1 and 2 and 5 out of the 10 mice/group for Study 3 (the mice subjected to blood biochemical examination). The organs and tissues were homogenized with 5\% 5-sulfosalicylic acid, and then centrifuged at $8,000 \times \mathrm{g}$ for $10 \mathrm{~min}$ at $4^{\circ} \mathrm{C}$. The resultant supernatants were diluted with distilled water, and finally, total GSH levels were determined with Total Glutathione Quantification Kit (Dojindo Laboratories, Kumamoto, Japan).

\section{Determination of drug-metabolizing enzymes}

To evaluate the induction or down-regulation of drug-metabolizing enzymes, liver microsomal and cytosolic fractions were prepared in Study 1. Briefly, each liver sample was mixed with $1.15 \% \mathrm{KCl}$ and homogenized. The homogenate was centrifuged at $9,000 \times \mathrm{g}$ for $20 \mathrm{~min}$ at $4^{\circ} \mathrm{C}$, and the supernatant was centrifuged at $105,000 \times \mathrm{g}$ for $60 \mathrm{~min}$ at $4^{\circ} \mathrm{C}$. The resultant supernatant was used as the cytosolic fraction. The pellet was resuspended with $1.15 \% \mathrm{KCl}$, and then centrifuged at $105,000 \times \mathrm{g}$ for $60 \mathrm{~min}$ at $4^{\circ} \mathrm{C}$. The resultant pellet was resuspended with $1.15 \% \mathrm{KCl}$ containing $20 \%$ glycerol, and then used as the microsomal fraction. Cytochrome P450 (P450) content was determined using the microsome by the method of Omura and Sato (1964). UDP-glucuronosyltransferase (UDPGT) activity to $p$-nitrophenol, one of the substrates that is metabolized by many UDP-GT isozymes, was determined using the microsome by the method of Bock et al. (1973). Glutathione $S$-transferase (GST) activities to two of the most major GST substrates, 1-chloro-2,4dinitrobenzene (CDNB) and 1,2-dichloro-4-nitrobenzene (DCNB), were measured using cytosol by the method of Habig et al. (1974). Protein concentrations of the microsome and cytosol were measured by the method of Lowry et al. (1951). Immunoblot analyses were performed using 2 out of the 4 cytosols/group according to the method of Laemmli (1970) and Burnette (1981). Briefly, cytosolic proteins (5 $\mu \mathrm{g}$ each) were separated by SDS-PAGE with $12.5 \%$ acrylamide slab gel. After the electrophoresis, proteins were electrophoretically transferred to a PVDF membrane (Daiichi Pure Chemicals, Co., Ltd., Tokyo, Japan), and this membrane was treated with the anti-rat GST Yc, Yb2 or Yp subunit antibody (Funakoshi, Co. Ltd., Tokyo, Japan). Immunochemically-reacted protein bands were visualized by chemiluminescence reagents. Anti-rat GST Yc, Yb2 and Yp subunit antibodies used for the present experiment are able to detect the alpha, $\mathrm{mu}$ and pi class GST isozymes in mice, respectively, and these antibodies do not cross-react with other class GST isozymes.

\section{Statistical analysis}

Mean values and standard deviations were calculated for each group. Statistical analyses were performed as described below. In Studies 1 and 3, Dunnett's test (Dunnett, 1955, 1964) was performed in order to analyze the effects of the BSO and APAP dosing, respectively. In Study 2, homogeneity of variance between the BSO dosing group and the control group was evaluated by the F test (JIS, 1965). Significant difference of the mean value between the dosing group and the control group at each time point was evaluated by Student's $t$-test (JIS, 1965) (for homoscedastic data) or Aspin-Welch's $t$-test (JIS, 1965) (for heteroscedastic data). These statistical analyses were all performed using SAS System Version 6.1.2 (SAS Institute Inc., NC, USA). The results were considered as statistically significant different when $\mathrm{p}<0.05$.

\section{RESULTS}

\section{Toxicity of BSO}

Toxicities of BSO were investigated in mice treated with BSO via drinking water for 14 days at dose levels of $0,5,10,20$ or $30 \mathrm{mM}$. Up to $30 \mathrm{mM}$ of BSO dosing, neither deaths nor abnormalities in clinical signs were observed throughout the BSO dosing period. The decreases in ratios of body weight change to the control were within $10 \%$, which is not regarded as an indication of toxicity (Fig. 2), and there was no avoidance of food or drink even at $30 \mathrm{mM}$ (data not shown). According to the results of organ weight determination (Table 1), a significant decrease in the liver weight (a $14.4 \%$ decrease for absolute weight and $8.2 \%$ decrease for relative weight) was observed in the group given $30 \mathrm{mM}$.

In the blood biochemical examination (Table 2), the AST level was significantly elevated in only the 30 $\mathrm{mM}$ group compared with the control group by $41.2 \%$. Though this change showed a possibility that some hepatic changes, including a decrease in liver weight, are induced by $30 \mathrm{mM}$ of BSO dosing, it was not inter- 
Novel model of continuous depletion of GSH induced by BSO.

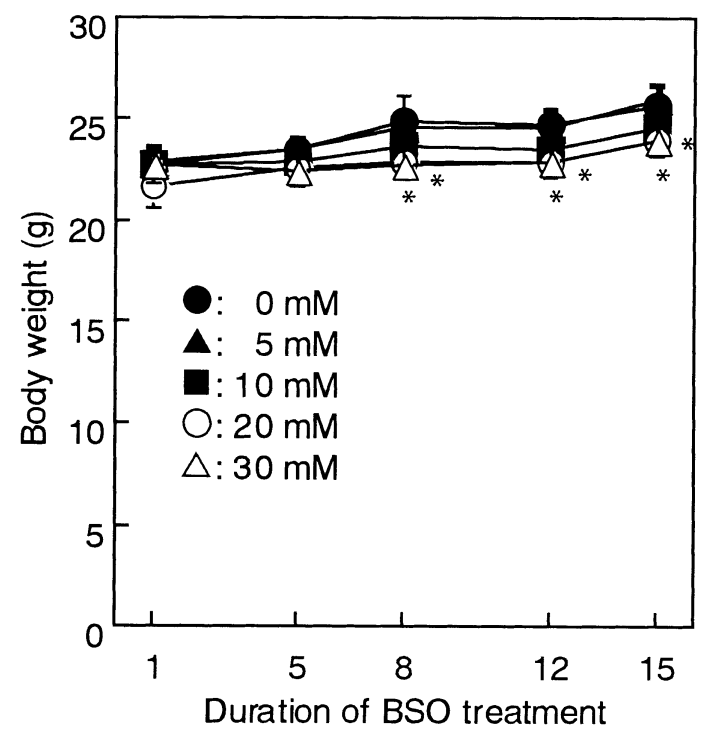

Fig. 2. Effect of BSO dosing via drinking water for 14 days on body weight change.

Each symbol represents the mean \pm SD of 4 mice.

*: Significantly different from the mean value of the control group ( $\mathrm{p}<0.05$, Dunnett's test). preted as liver injury judging from the fact that there were no changes in hepatic indicators such as ALT, ALP or T-BIL levels. The blood biochemical examination also showed a significant decrease in the TG level in the groups given 10, 20 and $30 \mathrm{mM}$ by $51.1,52.6$ and $64.1 \%$, respectively. In Study 2, however, remarkable circadian rhythm was observed in the TG level, which might have been caused by the timing of feeding, and the range of variation was 14.5 to $219.8 \mathrm{mg} / \mathrm{dL}$ for the control group and 9.5 to $127.0 \mathrm{mg} / \mathrm{dL}$ for the 20 $\mathrm{mM}$ BSO dosing group (Fig. 3). That is to say, the TG level in the $20 \mathrm{mM}$ BSO dosing group did not deviate much from the range of variation in the TG level in the control group. It was thus concluded that the decrease in the TG level was toxicologically not serious.

\section{Effect of BSO on the expression of drug-metaboliz- ing enzymes}

Drug-metabolizing enzymes were investigated in the liver of mice treated with BSO via drinking water for 14 days at dose levels of 0 to $30 \mathrm{mM}$. P450 content, UDP-GT activity to $p$-nitrophenol as a substrate and GST-CDNB activity were not influenced by the dosing

Table 1. Absolute and relative organ weights in mice treated with BSO via drinking water for 14 days.

\begin{tabular}{|c|c|c|c|c|c|}
\hline Tissue & $0 \mathrm{mM}$ & $5 \mathrm{mM}$ & $10 \mathrm{mM}$ & $20 \mathrm{mM}$ & $30 \mathrm{mM}$ \\
\hline \multicolumn{6}{|l|}{ Brain } \\
\hline Absolute (g) & $0.484 \pm 0.006$ & $0.476 \pm 0.019$ & $0.484 \pm 0.010$ & $0.479 \pm 0.016$ & $0.481 \pm 0.009$ \\
\hline Relative (g\%) & $1.888 \pm 0.074$ & $1.835 \pm 0.113$ & $1.968 \pm 0.053$ & $1.995 \pm 0.074$ & $2.008 \pm 0.097$ \\
\hline \multicolumn{6}{|l|}{ Heart } \\
\hline Absolute (g) & $0.115 \pm 0.006$ & $0.122 \pm 0.007$ & $0.120 \pm 0.004$ & $0.110 \pm 0.002$ & $0.111 \pm 0.005$ \\
\hline Relative (g\%) & $0.450 \pm 0.029$ & $0.473 \pm 0.039$ & $0.485 \pm 0.006$ & $0.458 \pm 0.015$ & $0.465 \pm 0.024$ \\
\hline \multicolumn{6}{|l|}{ Lung } \\
\hline Absolute (g) & $0.138 \pm 0.003$ & $0.136 \pm 0.010$ & $0.131 \pm 0.009$ & $0.132 \pm 0.009$ & $0.127 \pm 0.013$ \\
\hline Relative (g\%) & $0.535 \pm 0.017$ & $0.525 \pm 0.024$ & $0.530 \pm 0.029$ & $0.550 \pm 0.029$ & $0.530 \pm 0.050$ \\
\hline \multicolumn{6}{|l|}{ Liver } \\
\hline Absolute (g) & $1.499 \pm 0.091$ & $1.517 \pm 0.050$ & $1.411 \pm 0.058$ & $1.377 \pm 0.031$ & $1.284 \pm 0.074 * *$ \\
\hline Relative (g\%) & $5.845 \pm 0.301$ & $5.853 \pm 0.081$ & $5.728 \pm 0.075$ & $5.740 \pm 0.107$ & $5.363 \pm 0.307 *$ \\
\hline \multicolumn{6}{|l|}{ Spleen } \\
\hline Absolute (g) & $0.062 \pm 0.008$ & $0.066 \pm 0.006$ & $0.063 \pm 0.004$ & $0.062 \pm 0.002$ & $0.061 \pm 0.006$ \\
\hline Relative (g\%) & $0.243 \pm 0.030$ & $0.253 \pm 0.017$ & $0.255 \pm 0.013$ & $0.258 \pm 0.010$ & $0.253 \pm 0.021$ \\
\hline \multicolumn{6}{|l|}{ Kidney (R) } \\
\hline Absolute (g) & $0.216 \pm 0.008$ & $0.221 \pm 0.009$ & $0.200 \pm 0.017$ & $0.200 \pm 0.003$ & $0.203 \pm 0.011$ \\
\hline Relative (g\%) & $0.840 \pm 0.047$ & $0.850 \pm 0.029$ & $0.810 \pm 0.047$ & $0.833 \pm 0.022$ & $0.850 \pm 0.068$ \\
\hline \multicolumn{6}{|l|}{ Kidney (L) } \\
\hline Absolute (g) & $0.198 \pm 0.014$ & $0.197 \pm 0.011$ & $0.193 \pm 0.015$ & $0.202 \pm 0.012$ & $0.189 \pm 0.017$ \\
\hline Relative (g\%) & $0.773 \pm 0.060$ & $0.760 \pm 0.014$ & $0.785 \pm 0.044$ & $0.840 \pm 0.035$ & $0.788 \pm 0.087$ \\
\hline
\end{tabular}

The data of each parameter represent the mean \pm SD of 4 mice.

*, **: Significantly different from the mean value of the control group $(\mathrm{p}<0.05$ and $\mathrm{p}<0.01$, respectively, Dunnett's test). 
of BSO, however, GST-DCNB activity was significantly elevated in the groups given 10,20 or $30 \mathrm{mM}$ BSO (Fig. 4). In the immunoblot analyses of the cytosols, proteins cross-reacting with the anti-rat mu class GST subunit $\mathrm{Yb} 2$ antibody were slightly induced at 30 $\mathrm{mM}$, but there was little change in the proteins crossreacting with the anti-rat alpha or pi class GST subunit Yc or Yp antibody (Fig. 5). The possible interpreta-

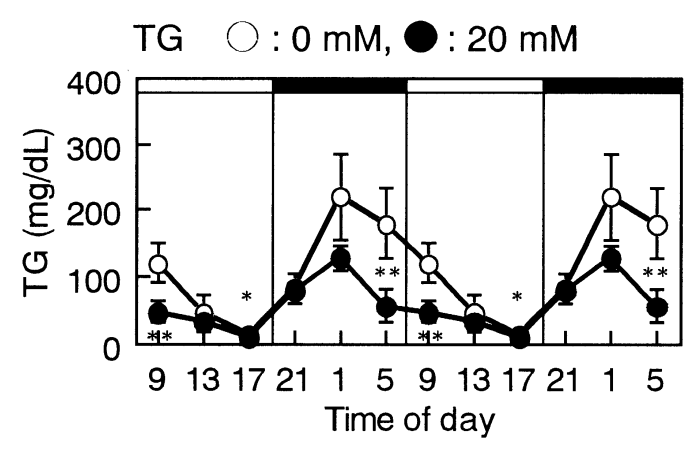

Fig. 3. Effect of BSO dosing via drinking water for 14 days on TG levels in plasma.

The data are shown with duplication in the second wave from the first. Each symbol represents the mean $\pm \mathrm{SD}$ of 4 mice. Open and closed bars illustrated in the upper region of the graph show the light and dark periods, respectively. $*, * *$ : Significantly different from the mean value of the control group ( $\mathrm{p}<0.05$ and $\mathrm{p}<0.01$, respectively, Student's $t$-test). tions for this slight induction of mu class isozyme(s) without changing of the GST-CDNB activity are some counterbalance to pi class GST isozyme(s) inactivated by the oxidative stress (Shen et al., 1984) and the inhibition of GSTs by BSO.

\section{GSH depletion by BSO dosing}

The effect of BSO on GSH depletion was investigated in mice treated with BSO via drinking water for 14 days at dose levels of 0 to $30 \mathrm{mM}$. The GSH levels were significantly and dose-dependently decreased by BSO dosing in all tissues measured (Fig. 6). As shown in Table 3, the area under the concentration-time curve (AUC) of GSH in mice given $20 \mathrm{mM}$ was decreased to $46.4 \%$ of that of the control mice in the liver, which showed the highest GSH level, and to 16.7, 16.3 and $19.6 \%$ of those of the control mice in the kidney, large intestine and heart, respectively. Only a $10.8 \%$ decrease was observed in the brain. Periodical examination showed that the GSH levels measured in all tissues from mice given $20 \mathrm{mM}$ were less than those from the control group at all the time points examined (Fig. 7). Thus, it was concluded that GSH was continuously depleted in mice treated with $20 \mathrm{mM}$ BSO via drinking water for 14 days.

\section{Potentiation of APAP-induced toxicity by BSO}

To investigate the possibility of whether APAPinduced toxicity was potentiated by simultaneous dosing of BSO, mice were treated with BSO via drinking

Table 2. Blood biochemical parameters in mice treated with BSO via drinking water for 14 days.

\begin{tabular}{|c|c|c|c|c|c|}
\hline Parameter & $0 \mathrm{mM}$ & $5 \mathrm{mM}$ & $10 \mathrm{mM}$ & $20 \mathrm{mM}$ & $30 \mathrm{mM}$ \\
\hline AST (U/L) & $42.0 \pm 5.0$ & $35.5 \pm 2.9$ & $39.0 \pm 3.6$ & $44.3 \pm 8.3$ & $59.3 \pm 4.3^{* *}$ \\
\hline ALT (U/L) & $28.3 \pm 1.7$ & $22.8 \pm 2.2$ & $21.0 \pm 1.0$ & \pm 12.1 & \pm 5.1 \\
\hline ALP (U/L) & $374.8 \pm 32.9$ & $402.0 \pm 34.5$ & $341.3 \pm 36.1$ & \pm 45.4 & \pm 85.1 \\
\hline T.BIL (mg/dL) & $0.030 \pm 0.018$ & $0.018 \pm 0.010$ & $0.030 \pm 0.000$ & $0.033 \pm 0.015$ & $0.023 \pm 0.026$ \\
\hline T.CHO (mg/dL) & $91.0 \pm 12.2$ & $95.0 \pm 6.5$ & $95.7 \pm 4.6$ & $99.3 \pm 6.4$ & $99.0 \pm 9.0$ \\
\hline TG (mg/dL) & $147.8 \pm 51.1$ & $120.0 \pm 30.0$ & $72.3 \pm 15.0 *$ & $\pm 14.7 * *$ & $\pm 10.3^{* *}$ \\
\hline GLU (mg/dL) & $252.8 \pm 2.6$ & \pm 24.4 & $250.7 \pm 36.9$ & \pm 63.2 & \pm 20.9 \\
\hline T.PRO (g/dL) & $4.63 \pm 0.28$ & $4.78 \pm 0.05$ & $4.77 \pm 0.06$ & $4.90 \pm 0.20$ & $4.70 \pm 0.14$ \\
\hline ALB (g/dL) & $1.53 \pm 0.10$ & $1.53 \pm 0.05$ & $1.53 \pm 0.06$ & $1.60 \pm 0.08$ & $1.58 \pm 0.05$ \\
\hline $\mathrm{A} / \mathrm{G}$ & $0.478 \pm 0.010$ & $0.470 \pm 0.008$ & $0.480 \pm 0.017$ & $0.483 \pm 0.017$ & $0.488 \pm 0.010$ \\
\hline $\mathrm{UN}(\mathrm{mg} / \mathrm{dL})$ & $34.83 \pm 6.63$ & $36.03 \pm 4.43$ & $34.30 \pm 5.56$ & $30.23 \pm 1.80$ & $29.03 \pm 5.15$ \\
\hline CRE (mg/dL) & $0.095 \pm 0.013$ & $0.098 \pm 0.005$ & $0.097 \pm 0.023$ & $0.085 \pm 0.006$ & $0.100 \pm 0.038$ \\
\hline $\mathrm{Ca}(\mathrm{mg} / \mathrm{dL})$ & $9.78 \pm 0.22$ & $10.03 \pm 0.21$ & $9.97 \pm 0.32$ & $10.13 \pm 0.66$ & $9.80 \pm 0.36$ \\
\hline IP (mg/dL) & $7.725 \pm 1.926$ & $7.855 \pm 1.000$ & $6.617 \pm 1.432$ & $7.868 \pm 2.318$ & $7.363 \pm 0.595$ \\
\hline
\end{tabular}

The data of each parameter represent the mean \pm SD of 4 mice.

*, **: Significantly different from the mean value of the control group ( $\mathrm{p}<0.05$ and $\mathrm{p}<0.01$, respectively, Dunnett's test). 
Novel model of continuous depletion of GSH induced by BSO.

water at the concentration of 0 or $20 \mathrm{mM}$, in combination with APAP via the diet at the concentration of 0 , 0.125 or $0.25 \%$ for 14 days. In the group given both 20

Table 3. AUC of GSH in mice treated with or without $20 \mathrm{mM}$ BSO.

\begin{tabular}{lrrc}
\hline Tissue & \multicolumn{2}{c}{ AUC of GSH } & \multirow{2}{*}{$\begin{array}{c}\text { AUC ratio, \% } \\
(20 \mathrm{mM} / 0 \mathrm{mM})\end{array}$} \\
\cline { 2 - 3 } & $0 \mathrm{mM}$ & $20 \mathrm{mM}$ & 46.4 \\
Liver & 182.3 & 84.6 & 16.7 \\
Kidney & 52.1 & 8.7 & 89.2 \\
Brain & 38.1 & 34.0 & 50.4 \\
Lung & 48.8 & 24.6 & 19.6 \\
Heart & 30.6 & 6.0 & 51.5 \\
Spleen & 72.0 & 37.1 & 27.0 \\
Pancreas & 33.7 & 9.1 & 32.4 \\
Small intestine & 72.2 & 23.4 & 16.3 \\
Large intestine & 52.6 & 8.6 & 28.6 \\
Skeletal muscle & 18.5 & 5.3 & 52.5 \\
Plasma & 580.1 & 304.5 & 54.4 \\
Blood cells & 39559.6 & 21528.8 & \\
\hline
\end{tabular}

The area under the concentration-time curve (AUC) is expressed as $\mu \mathrm{mol} \cdot \mathrm{hr} / \mathrm{L}$ for plasma and blood cells, and $\mu \mathrm{mol}$. $\mathrm{hr} / \mathrm{g}$ tissue for other tissues and organs.
$\mathrm{mM} \mathrm{BSO}$ and $0.25 \%$ APAP, 9 out of the 10 mice died on Day 2. As shown in Table 4, the ALT and CRE levels in the one animal which survived on Day 2 were remarkably elevated to $23300 \mathrm{U} / \mathrm{L}$ for ALT and $1.2 \mathrm{mg} /$ $\mathrm{dL}$ for CRE, suggesting that severe injury was induced in the liver and kidney in this group. In order to investigate the liver and kidney injury in detail, this one mouse and all the 10 mice given $0.25 \%$ APAP alone were provisionally autopsied on Day 2 . Remarkable necrosis of hepatocytes, especially in the central zone of the hepatic lobule (Photo 1), and renal tubular epi-

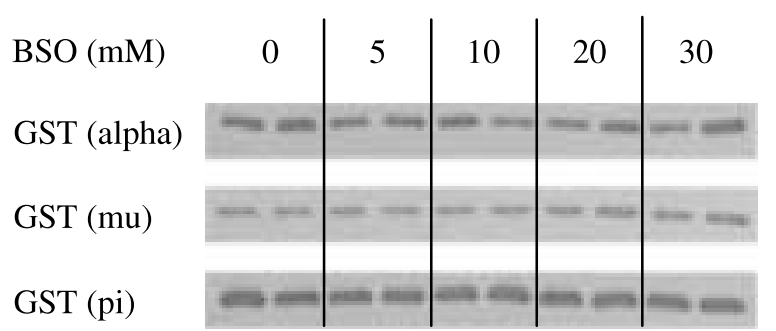

Fig. 5. Immunoblot analysis of liver cytosolic proteins from control and BSO-treated mice using anti-rat GST subunit antibodies.
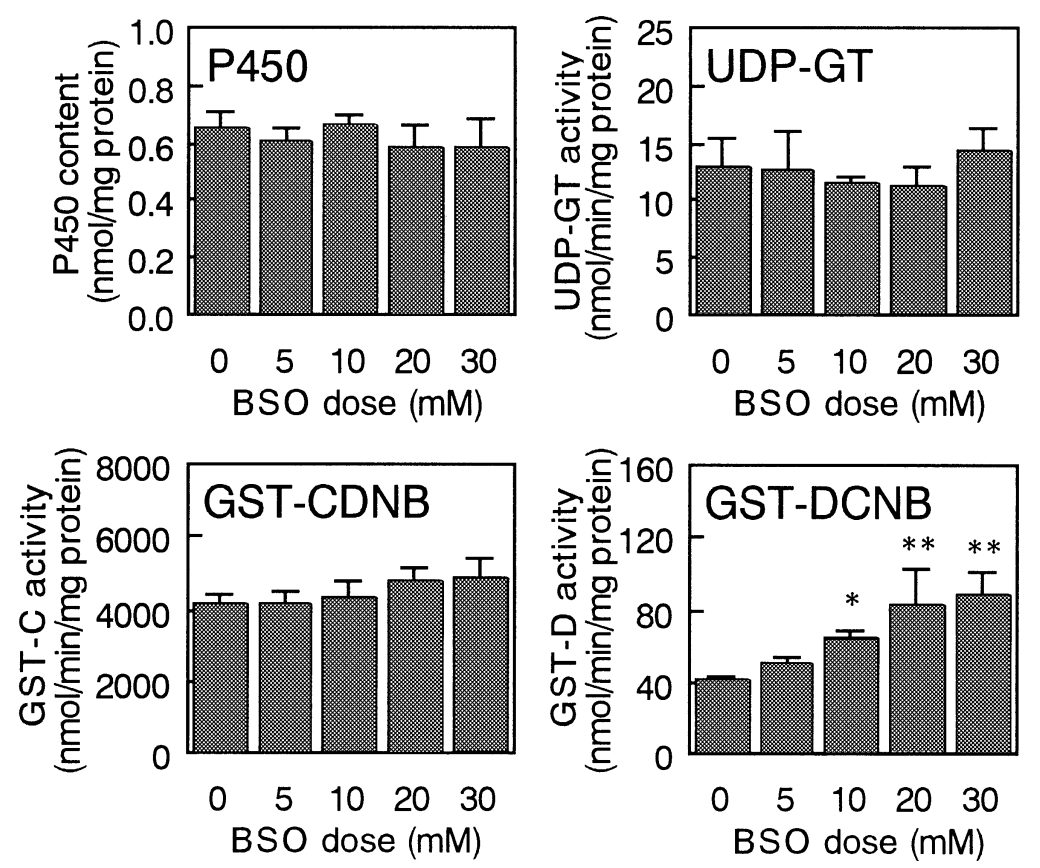

Fig. 4. Effect of BSO dosing via drinking water for 14 days on liver P450 content, UDP-GT activity and GST activities.

Each bar represents the mean \pm SD of 4 mice. *, **: Significantly different from the mean value of the control group $(p<0.05$ and $p<0.01$, respectively, Dunnett's test). 
thelium (Photo 2), was observed in mice given both 20 $\mathrm{mM}$ BSO and $0.25 \%$ APAP. These severe injuries were consistent with the elevation in levels of ALT and CRE. However, there were no histopathological abnormalities in the liver or kidney in mice given $0.25 \%$ APAP alone (Photo 1 and 2), or in other organs or tissues of mice of either group.

In the case of $0.125 \%$ APAP, the coadministration of $20 \mathrm{mM}$ BSO resulted in the elevation of the ALT level up to about 100 times higher than that in the
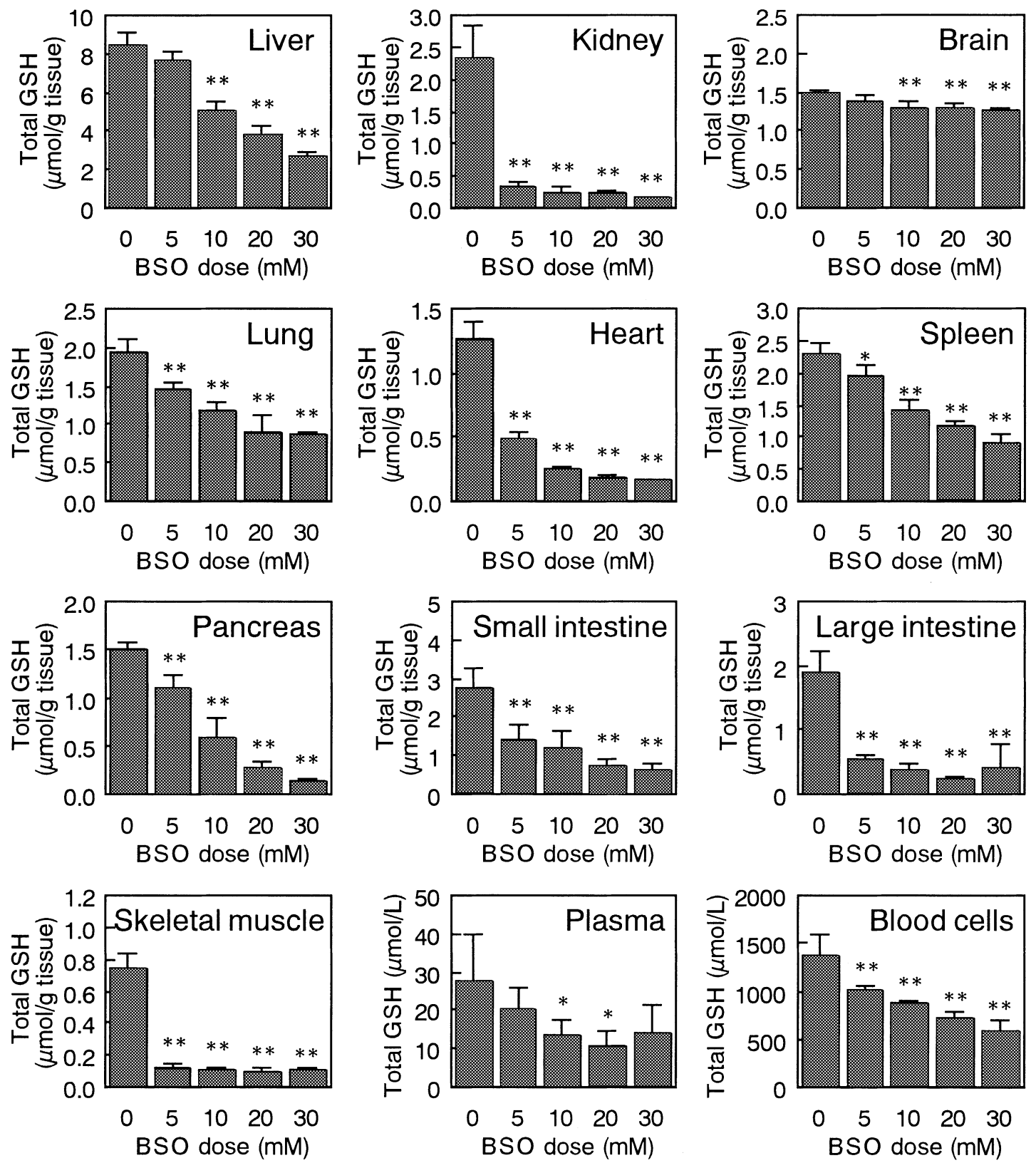

Fig. 6. Effect of BSO dosing via drinking water for 14 days on total GSH levels in various tissues.

Each bar represents the mean \pm SD of 4 mice. *, **: Significantly different from the mean value of the control group ( $\mathrm{p}<0.05$ and $\mathrm{p}<0.01$, respectively, Dunnett's test). 
Novel model of continuous depletion of GSH induced by BSO.

group given $20 \mathrm{mM}$ BSO or $0.125 \%$ APAP on Day 2 (Table 4). In this coadministration group, focal necrosis of hepatocytes with proliferation of fibroblasts was observed in some mice on Day 15 (Photo 3), even though the ALT level elevated on Day 2 was returned to the basal level on Day 15 (Table 4). In other groups, i.e. the control, $20 \mathrm{mM}$ BSO alone and $0.125 \%$ APAP alone groups, no histopathological abnormalities were observed in the liver (Photo 3). No histopathological abnormalities in other organs or tissues including the kidney were observed in any group including the coadministration group. Throughout the dosing period, no abnormalities in general conditions were observed in any but one animal. The exception was a mouse given both $20 \mathrm{mM}$ BSO and $0.125 \%$ APAP in which irregular respiration was observed on Days 4 and 5. There were no statistically significant effects of the $0.125 \%$ APAP dosing on body weight, food intake or hematological parameters regardless of the level of BSO dosing.
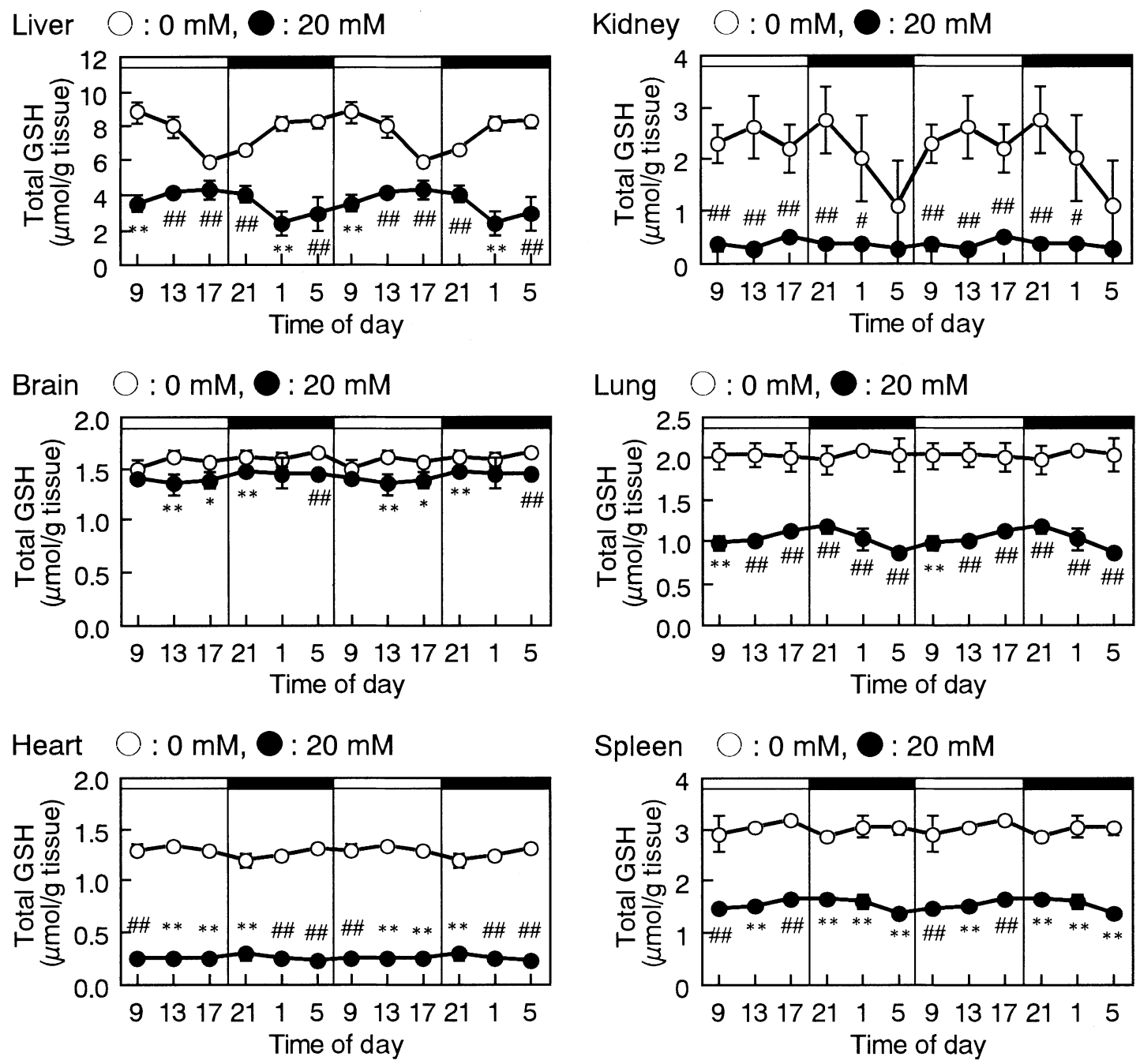

Fig. 7. Effect of BSO dosing via drinking water for 14 days on total GSH levels in various tissues.

The data are shown with duplication in the second wave from the first. Each symbol represents the mean \pm SD of 4 mice. Open and closed bars illustrated in the upper region of the graph show the light and dark periods, respectively. *, **: Significantly different from the mean value of the control group $(\mathrm{p}<0.05$ and $\mathrm{p}<0.01$, respectively, Student's $t$-test). \#, \#\#: Significantly different from the mean value of the control group ( $\mathrm{p}<0.05$ and $\mathrm{p}<0.01$, respectively, Aspin-Welch's $t$-test). 
The GSH levels in the liver and kidney of one animal coadministered $20 \mathrm{mM}$ BSO and $0.25 \%$ APAP, which was the sole survivor in its group on Day 2, were decreased to $70 \%$ (liver) and $61 \%$ (kidney) of those in mice given $20 \mathrm{mM}$ BSO alone. However, there were no statistically significant effects of the $0.125 \%$ APAP dosing on GSH levels (data not shown).
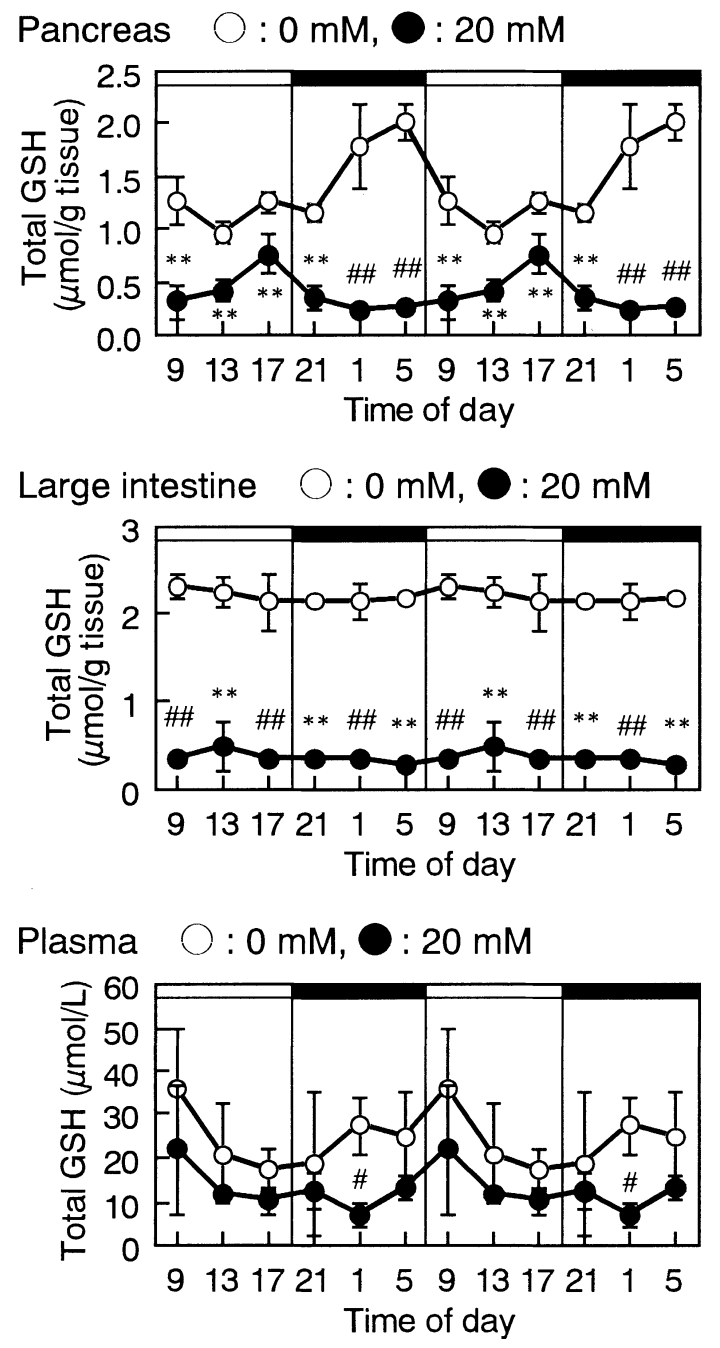

\section{DISCUSSION}

In the present study, we tried to validate an animal model with continuously depleted levels of GSH in order to sensitively detect the toxicity induced by chemicals which are metabolized to electrophilic and reactive metabolite(s) including intermediate(s). Mice were treated with BSO, an inhibitor of GSH synthesis, via drinking water for 14 days at dose levels of 0 to 30 $\mathrm{mM}$, to investigate not only the effects of BSO on GSH
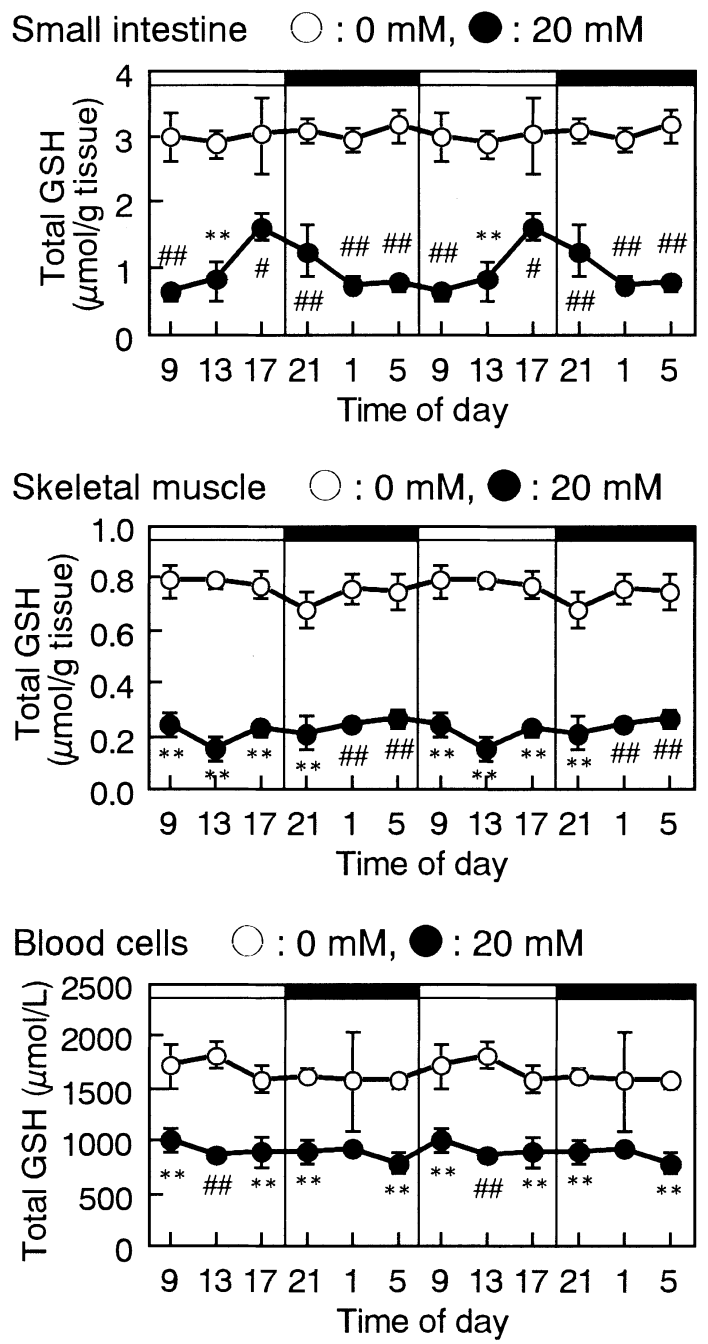

Fig. 7 (continued). Effect of BSO dosing via drinking water for 14 days on total GSH levels in various tissues. The data are shown with duplication in the second wave from the first. Each symbol represents the mean \pm SD of 4 mice. Open and closed bars illustrated in the upper region of the graph show the light and dark periods, respectively. **: Significantly different from the mean value of the control group ( $\mathrm{p}<0.01$, Student's $t$-test). \#, \#\#: Significantly different from the mean value of the control group $(\mathrm{p}<0.05$ and $\mathrm{p}<0.01$, respectively, Aspin-Welch's $t$-test). 
Novel model of continuous depletion of GSH induced by BSO.

levels but also the toxicity of BSO including changes in the expression of liver drug-metabolizing enzymes. A significant decrease in liver weight observed in the 30 $\mathrm{mM}$ group suggested that $\mathrm{BSO}$ at $30 \mathrm{mM}$ is toxicologically too sensitive to be used. On the other hand, a 14day dosing of $20 \mathrm{mM}$ or less of BSO to mice resulted in no toxicity. The GSH measurement demonstrated that the GSH levels after treatment with $20 \mathrm{mM}$ BSO were decreased to less than about $50 \%$ of those of the control in all tissues measured except for the brain. By drug-metabolizing enzyme measurement, induction of the mu class GST isozymes(s) was observed after 30 $\mathrm{mM}$ dosing of BSO. Totally, GSH conjugation activity in vivo would be decreased by BSO dosing, because of the considerable decrease in GSH level, which is essential for GSH conjugation. No noteworthy changes were observed in the P450 content or UDP-GT activity to $p$-nitrophenol as a substrate. Based on these results, a mouse treated with BSO mixed in the drinking water for 14 days at a dose level of $20 \mathrm{mM}$ was concluded to be an animal model in which GSH levels were depleted in various organs without toxicity.

A single intravenous dose study of BSO (1.6 g/ $\mathrm{kg}$ ) in mice has been reported. However, only a $17 \%$ decrease in the GSH level comparing to the control was shown in the liver at $15 \mathrm{hr}$ after BSO dosing even though there was about a $65 \%$ decrease at $6 \mathrm{hr}$ after BSO dosing (Drew and Miners, 1984). Moreover, remarkable circadian rhythm has been reported in the GSH levels for some tissues such as the liver and pancreas (White et al., 1987; Tunon et al., 1992; Boughattas et al., 1996; Neuschwander-Tetri and Rozin, 1996). So, it was not clear whether or not the GSH level in mice treated with BSO via drinking water would show a low value over an extended period such as $24 \mathrm{hr}$. In the present investigation, to complete the assessment of the GSH-depleted model, the effect of the BSO dosing on GSH levels was investigated every $4 \mathrm{hr}$ in mice treated with BSO mixed in the drinking water for 14 days at a dose level of $20 \mathrm{mM}$. The results demonstrate that the GSH levels in all tissues measured were lower in the $20 \mathrm{mM}$ BSO dosing group than those in the control group at all the time points measured. Based on these results, it was concluded that GSH levels were continuously depleted and the decrease was independent of the circadian rhythm in mice treated with BSO via drinking for 14 days.

The variety of decreasing ratios of GSH levels in various tissues can be discussed in this paper. In the 20 $\mathrm{mM}$ group, a 53.6\% decrease was observed in the liver, and a more than $80 \%$ decrease was observed in the kidney, heart and large intestine. However, only a $10.8 \%$ decrease was observed in the brain. These differences in decreasing ratios appear to be related to several factors such as the distribution of BSO, the rate of GSH turnover which would be affected by the expression or activity of $\gamma$-GCS, the supply of cysteine which is essential for GSH synthesis, consumption of GSH and so on. It has been reported that marked reduction of brain GSH was observed following intracerebroventricular administration of BSO to rats (Pileblad and Magnusson, 1988), indicating that the small decrease in brain GSH observed in the present study would be due to poor distribution of BSO by virtue of the blood brain barrier.

Finally, we investigated whether APAP-induced toxicity could be potentiated in mice with continuously depleted levels of GSH by BSO dosing. Remarkable injury in the liver and kidney was observed in mice given both $20 \mathrm{mM} \mathrm{BSO}$ and $0.25 \%$ APAP, and 9 out of the 10 mice died on Day 2. However, no toxicity was observed in mice given $0.25 \%$ APAP alone. Judging from these results, it could be hypothesized that, in mice given both $20 \mathrm{mM} \mathrm{BSO}$ and $0.25 \%$ APAP, the

Table 4. Blood biochemical parameters (ALT and CRE) in mice treated with BSO and APAP.

\begin{tabular}{|c|c|c|c|c|c|}
\hline \multirow{2}{*}{$\begin{array}{l}\text { Day of } \\
\text { measurement }\end{array}$} & \multirow[b]{2}{*}{ Group } & \multicolumn{2}{|c|}{ ALT (U/L) } & \multicolumn{2}{|c|}{ CRE (mg/dL) } \\
\hline & & $0 \mathrm{mM}$ BSO & $20 \mathrm{mM}$ BSO & $0 \mathrm{mM}$ BSO & $20 \mathrm{mM} \mathrm{BSO}$ \\
\hline \multirow[t]{3}{*}{ Day 2} & $0 \%$ APAP & $28.1 \pm 13.7$ & $29.2 \pm 17.4$ & $0.16 \pm 0.08$ & $0.00 \pm 0.00$ \\
\hline & $0.125 \%$ APAP & $26.9 \pm 10.4$ & $2662.7 \pm 8094.7$ & $0.02 \pm 0.06$ & $0.02 \pm 0.06$ \\
\hline & $0.25 \%$ APAP & $31.7 \pm 13.6$ & 23300 & $0.17 \pm 0.09$ & 1.20 \\
\hline \multirow[t]{2}{*}{ Day 15} & $0 \%$ APAP & $26.4 \pm 4.2$ & $22.0 \pm$ & $0.09 \pm 0.01$ & $0.10 \pm 0.02$ \\
\hline & $0.125 \%$ APAP & $29.0 \pm 3.2$ & $41.1 \pm$ & $0.10 \pm 0.01$ & $0.11 \pm 0.03$ \\
\hline
\end{tabular}

The data of the parameters on Day 2 represent the mean \pm SD of 10 mice except for the group that was dosed $20 \mathrm{mM}$ BSO and $0.25 \%$ APAP simultaneously. The data of the parameters of the one mouse that survived on Day 2 are shown for this group. The data of parameters on Day 15 represent the mean \pm SD of 5 mice. 
T. WATANABE et al.
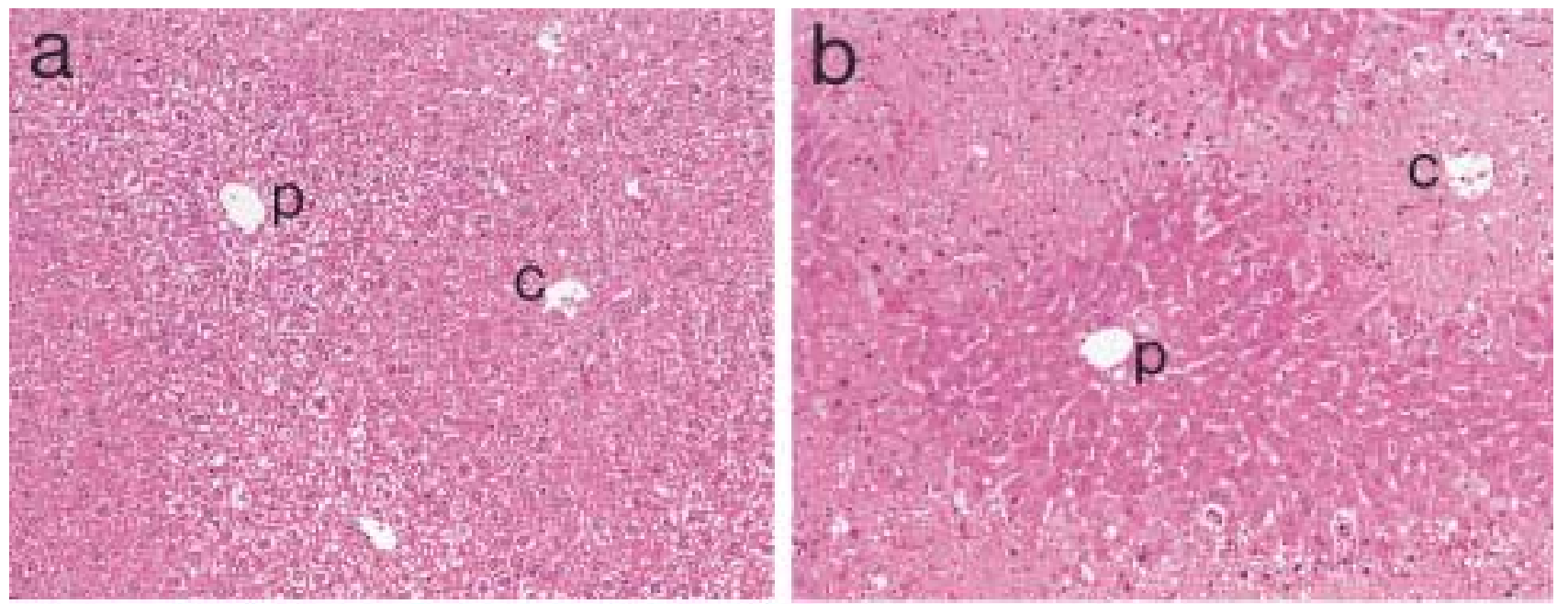

Photo 1. H\&E-stained sections of mouse liver on Day 2 after $0.25 \%$ APAP treatment (a), and both 20 mM BSO and $0.25 \%$ APAP treatment (b).

C, central vein; P, portal triad. $\times 108$
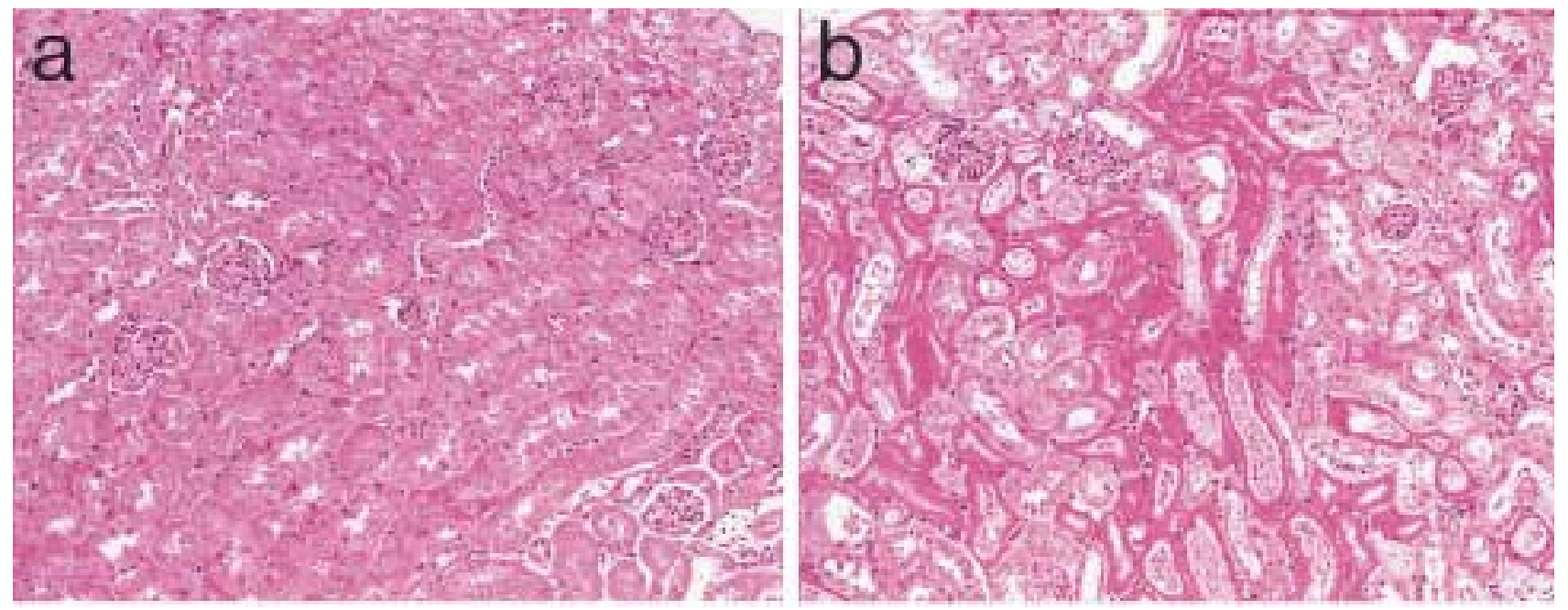

Photo 2. H\&E-stained sections of mouse kidney on Day 2 after $0.25 \%$ APAP treatment (a), and both $20 \mathrm{mM}$ BSO and $0.25 \%$ APAP treatment (b).

$\times 108$ 
Novel model of continuous depletion of GSH induced by BSO.
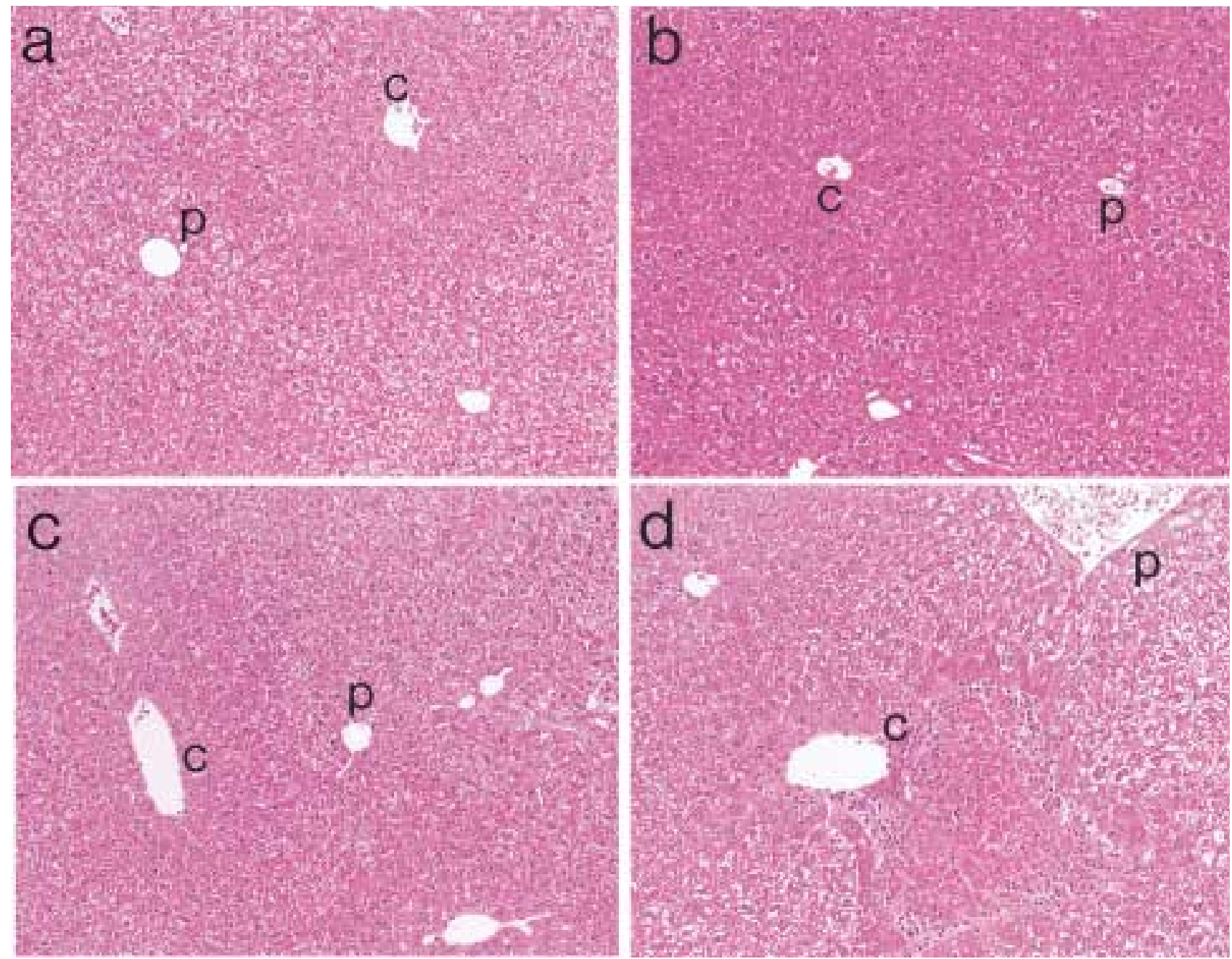

Photo 3. H\&E-stained sections of mouse liver on Day 15 after non-treatment (a), 20 mM BSO treatment (b), $0.125 \%$ APAP treatment (c) and both $20 \mathrm{mM}$ BSO and $0.125 \%$ APAP treatment (d).

C, central vein; $\mathrm{P}$, portal triad. $\times 108$ 
proteins in the hepatocytes and renal tubular epithelium seem to be covalently or oxidatively modified with the reactive metabolite(s) of APAP because of depletion of the scavenger, GSH. In mice given both 20 $\mathrm{mM}$ BSO and $0.125 \%$ APAP, liver injury with remarkable ALT-elevation (2663 U/L) was also observed on Day 2. This ALT elevation, however, returned to within normal range on Day 15. Histopathological examination showed focal necrosis of hepatocytes with proliferation of fibroblasts in some mice given both $20 \mathrm{mM}$ BSO and $0.125 \%$ APAP. These phenomena might be interpreted as follows: the hepatic injury induced on Day 2 resulted in the suppression of the metabolism from APAP to reactive metabolite(s), thus allowing the damage to recover.

As described above, APAP-induced toxicity could be potentiated in mice with continuously depleted levels of GSH by BSO dosing. This result suggests that this continuous GSH-depleted mouse is more sensitive against toxicity induced by chemicals which are metabolized to electrophilic and reactive metabolite(s) including intermediate(s) than normal mice. An idiosyncratic toxicity is usually induced in patients with an idiosyncratic toxicant at extremely low incidence, and it is difficult to reproduce such idiosyncrasy in experimental animals (Knowles et al., 2000; Ju and Uetrecht, 2002). Generally, two types of idiosyncratic toxicity have been known (Pirmohamed et al., 1996; Toda, 1999): one is immunologically induced allergic toxicity, and the other one is toxicity induced by genetically abnormal drug metabolism. In both cases, covalent binding of electrophilic and reactive metabolite(s) including intermediate(s) to the intracellular proteins is considered to be one of the key events for idiosyncratic toxicity (Pumford and Halmes, 1997; Knowles et al., 2000; Petersen, 2002). Thus, administration of an idiosyncratic toxicant to established GSH-depleted mice could reproduce the idiosyncratic event.

In conclusion, an animal model, in which GSH levels were continuously depleted in various organs without toxicity, was established by 14-day dosing of BSO via drinking water to the mouse at a dose level of $20 \mathrm{mM}$. It was strongly suggested that this animal model shows high susceptibility to toxicity induced by chemicals which are metabolized to electrophilic and reactive metabolite(s) including intermediate(s). The animal model established and validated in this study could be useful for investigation in the field of idiosyncratic drug reactions.

\section{ACKNOWLEDGMENT}

We are particularly grateful to Ms. Hitomi Terada, Keiko Muramatsu and Kaori Kato for their advice and technical assistance. We also wish to express our thanks to Ms. Caroline Bertorelli for proofreading of this manuscript.

\section{REFERENCES}

Bock, K.W., Fröhling, W., Remmer, H. and Rexer, B. (1973): Effects of phenobarbital and 3-methylcholanthrene on substrate specificity of rat liver microsomal UDP-glucuronyltransferase. Biochim. Biophys. Acta, 327, 46-56.

Boughattas, N.A., Li, X.M., Filipski, J., Lemaigre, G., Filipski, E., Bouzouita, K., Belhadj, O. and Levi, F. (1996): Modulation of cisplatin chronotoxicity related to reduced glutathione in mice. Hum. Exp. Toxicol., 15, 563-572.

Boyer, T.D. and Rouff, S.C. (1971): Acetaminopheninduced hepatic necrosis and renal failure. J. Am. Med. Assoc., 218, 440-441.

Burnette, W.N. (1981): "Western blotting": Electrophoretic transfer of proteins from sodium dodecyl sulfate-polyacrylamide gels to unmodified nitrocellulose and radiographic detection with antibody and radioiodinated protein A. Anal. Biochem., 112, 195-203.

Coles, B. and Ketterer, B. (1990): The role of glutathione and glutathione transferases in chemical carcinogenesis. Crit. Rev. Biochem. Mol. Biol., 25, 47-70.

Dahlin, D.C., Miwa, G.T., Lu, A.Y.H. and Nelson, S.D. (1984): $N$-acetyl- $p$-benzoquinone: A cytochrome P-450-mediated oxidation product of acetaminophen. Proc. Natl. Acad. Sci. USA, 81, 1327-1331.

Drew, R. and Miners, J.O. (1984): The effects of buthionine sulfoximine (BSO) on glutathione depletion and xenobiotic biotransformation. Biochem. Pharmacol., 33, 2989-2994.

Dunnett, C. W. (1955): A multiple comparisons procedure for comparing several treatments with a control. J. Am. Stat. Assoc., 50, 1096-1121.

Dunnett, C. W. (1964): New tables for multiple comparisons with a control. Biometrics, 20, 482-491.

Griffith, O.W. (1982): Mechanism of action, metabolism, and toxicity of buthionine sulfoximine and its higher homologs, potent inhibitors of glutathione synthesis. J. Biol. Chem., 257, 13704- 
Novel model of continuous depletion of GSH induced by BSO.

13712.

Griffith, O.W. and Meister, A. (1979a): Potent and specific inhibition of glutathione synthesis by buthionine sulfoximine (S-n-butyl homocysteine sulfoximine)*. J. Biol. Chem., 254, 7558-7560.

Griffith, O.W. and Meister, A. (1979b): Glutathione: Interorgan translocation, turnover, and metabolism. Proc. Natl. Acad. Sci., 76, 5606-5610.

Habig, W.H., Pabst, M.J. and Jakoby, W.B. (1974): Glutathione S-transferases. The first enzymatic step in mercapturic acid formation. J. Biol. Chem., 249, 7130-7139.

Hinson, J.A. (1980): Biochemical toxicology of acetaminophen. Rev. Biochem. Toxicol., 2, 103-129.

JIS (1965): The $t$-test with F-test for homogeneity of variance. Significance test of difference between the two population means (standard deviations unknown, two-sided). Japanese Industry Standard Z9049.

$\mathrm{Ju}, \mathrm{C}$. and Uetrecht, J.P. (2002): Mechanism of idiosyncratic drug reactions: Reactive metabolites, formation, protein binding and the regulation of the immune system. Curr. Drug Metab., 3, 367-377.

Knowles, S.R., Uetrecht, J. and Shear, N.H. (2000): Idiosyncratic drug reactions: The reactive metabolite syndromes. The Lancet, 356, 1587-1591.

Laemmli, U.K. (1970): Cleavage of structural proteins during the assembly of the head of bacteriophage T4. Nature, 227, 680-685.

Lowry, O.H., Rosebrough, N.J., Farr, A.L. and Randall, R.J. (1951): Protein measurement with the folin phenol reagent. J. Biol. Chem., 193, 265-275.

Lu, S.C. (1999): Regulation of hepatic glutathione synthesis: Current concepts and controversies. FASEB J., 13, 1169-1183.

Miners, J.O., Drew, R. and Birkett, D.J. (1984): Mechanism of action of paracetamol protective agents in mice in vivo. Biochem. Pharmacol., 33, 29953000 .

Mizutani, T., Nomura, H., Nakanishi, K. and Fujita, S. (1987): Hepatotoxicity of butylated hydroxytoluene and its analogs in mice depleted of hepatic glutathione. Toxicol. Appl. Pharmacol., 87, 166-176.

Mizutani, T., Murakami, M., Shirai, M., Tanaka, M. and Nakanishi, K. (1999): Metabolism-dependent hepatotoxicity of methimazole in mice depleted of glutathione. J. Appl. Toxicol., 19, 193-198.

Moldeus, P., Andersson, B., Rahimtula, A. and
Berggren, M. (1982): Prostaglandin synthetase catalyzed activation of paracetamol. Biochem. Pharmacol., 31, 1363-1368.

Neuschwander-Tetri, B.A. and Rozin, T. (1996): Diurnal variability of cysteine and glutathione content in the pancreas and liver of the mouse. Comp. Biochem. Physiol. Part B Biochem. Mol. Biol., 114, 91-95.

Omura, T. and Sato, R. (1964): The carbon monoxidebinding pigment of liver microsomes. I. Evidence for its hemoprotein nature. J. Biol. Chem., 239, 2370-2378.

Petersen, K.U. (2002): From toxic precursors to safe drugs. Mechanisms and relevance of idiosyncratic drug reactions. Arzneimittelforchung, 52, 423-429.

Pileblad, E. and Magnusson, T. (1988): Marked reduction of rat brain glutathione following intracerebroventricular administration of the glutathione synthesis inhibitor L-buthionine sulfoximine. Neurosci. Lett., 95, 302-306.

Pirmohamed, M., Madden, S. and Park, B.K. (1996): Idiosyncratic drug reactions. Metabolic bioactivation as a pathogenic mechanism. Clin. Pharmacokinet., 31, 215-230.

Poppel, G., Vogel, N., Balderen, P.J. and Kok, F.J. (1992): Increased cytogenetic damage in smokers deficient in glutathione S-transferase isozyme mu. Carcinogenesis, 13, 303-305.

Pumford, N.R. and Halmes, N.C. (1997): Protein targets of xenobiotic reactive intermediates. Annu. Rev. Pharmacol. Toxicol., 37, 91-117.

Reed, D.J. (1986): Regulation of reactive processes by glutathione. Biochem. Pharmacol., 35, 7-13.

Shen, H.X., Tamai, K., Satoh, K., Hatayama, I., Tsuchida, S. and Sato, K. (1991): Modulation of class Pi glutathione transferase activity by sulfhydryl group modification. Arch. Biochem. Biophys., 286, 178-182.

Toda, G. (1999): Liver injury induced by troglitazone. Endcrin. Diatetology, 9, 393-400.

Tunon, M.J., Gonzalez, P., Lopez, P., Salido, G.M. and Madrid, J.A. (1992): Circadian rhythms in glutathione and glutathione $S$-transferase activity of rat liver. Arch. Int. Physiol. Biochim. Biophys., 100, 83-87.

White, B.P., Davies, M.H. and Schnell, R.C. (1987): Circadian variations in hepatic glutathione content, $\gamma$-glutamylcysteine synthetase and $\gamma$ glutamyltransferase activities in mice. Toxicol. Lett., 35, 217-223. 